\title{
Meditation and Mindfulness in the Peer-Reviewed Literature: Review
}

\author{
June Kume* \\ Department of Physical Therapy, USA
}

Submission: February 28, 2018; Published: July 17, 2018

*Corresponding author: June Kume, Touro College, Department of Physical Therapy, 1700 Union Blvd, Bay Shore, NY 11706, USA, Email: June. Kume@Touro.edu

\begin{abstract}
Meditation and mindfulness are practices that have become readily accepted within the mainstream Westernized culture, as evidenced by the plethora of widely available ways to implement them via online, written, and in-person resources. Expanding evidence demonstrating the beneficial physical and psychological consequences of adhering to these approaches are becoming better understood. As a result, the acceptance to use these approaches in practical applications appears to have become slowly more integrated within medical and scientific investigations over the past twenty years. The current discussion reviews the trending changes in publications of peer-reviewed medical and scientific literature encompassing these topics while providing insight as to the possible reasons why these changes have occurred. Based upon these empirical observations, it is anticipated that there will be further future upswings in usage for these approaches within clinical rehabilitation settings, including within the area of physical therapy.
\end{abstract}

Keywords: Applications; Trends; Healthcare; Clinical rehabilitation

\section{Introduction}

Meditation and mindfulness are centuries old practices with deep roots originating from Eastern religions of Hinduism and Buddhism. The underlying principles for each concept are intrinsically simple in nature. Meditation is an "actionable" term denoting a large group of methodologies meant to focus one's attention, usually by emphasizing the visceral sensation of breathing. Chodron P [1] refers to this as "an invitation to notice when we reach our limit and to not get carried away by hope and fear"[1]. Mindfulness refers to the cognitive process of "paying attention in a particular way: on purpose, in the present moment, and non-judgmentally"[2]. Once perceived as a non-scientific and spiritual approach espoused by only a small subsection of Westernized society, these concepts have broadened considerably over the last twenty years to be embraced by larger communities, and more specifically, the scientific and healthcare professions.

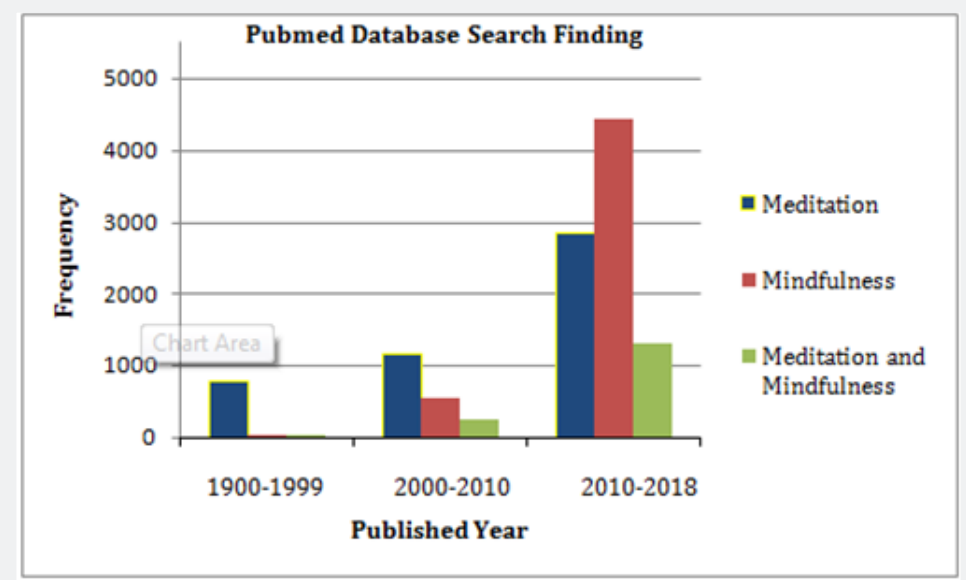

Figure 1: Increasing frequency of articles generated from PubMed database searches from 1900 to 1999; 2000-2010, and 2010-2018 using the search terms noted in graph. 
Focused searches of PubMed, a database specifically utilized for biomedical and life sciences journals maintained by the US National Library of Medicine and National Institutes of Health (NLM/NIH), supports the view that these two practices within the scientific and medical community are increasingly under scrutiny (PubMed, accessed on 02/26/2018, https://www.ncbi. nlm.nih.gov/pubmed/). Inputting the search term, "meditation" with a filter spanning the years from 1900 to 1999, generated 775 publications results. Similarly, the search term, "mindfulness" yielded 39 articles, and the combination of the two terms ("meditation AND mindfulness") yielded only 23 articles. In contrast, articles searched in the early 21st century (2000 to 2010) had an overall increase in publications for all three terms, with "meditation" yielding 1148 articles, "mindfulness" presenting 555 articles, and the combination resulting in 244 hits. When considering the last eight years of publications, the upward trend is even more pronounced. For this time period (2010 to 2018), the term "meditation" yielded 2842 results (representing a 248\% increase from the prior decade), "mindfulness" yielded 4435 (representing an astonishing $799 \%$ increase), and in the combined phrase of "meditation AND mindfulness" produced a total yield of 1312 article hits (a 538\% increase). The trajectory (Figure 1) of peer-reviewed publications over time suggests a widening acceptance of these traditionally Eastern approaches within more largely Westernized scientific circles.

In order to view how these interventions were being studied with relation to clinical rehabilitation objectives, a search was done looking specifically at their relation to physical therapy, a discipline that some have reported to be conducive for these practices[3]. For this more focused search, it was found that the number of physical therapy publications related to mindfulness and meditation has also been increasing, albeit on a much smaller scale. Within the last time period (2010 to 2018) for example, 12 articles have been published with respect to "mindfulness AND physical therapy"; of those only two were clinical trials and the remainder were reviews. For studies which referenced "meditation AND physical therapy", the number of articles generated were 15 ( 7 clinical trials and 8 reviews). Prior to that period, only 4 studies ( 1 clinical, 3 reviews) were noted for "meditation" and "physical therapy"; none were noted for "mindfulness" and physical therapy.

Overall, these peer reviewed studies have supported application of meditation and mindfulness in multiple non-clinical and clinical settings. Subject participants have encompassed extremely diverse populations, including graduate and medical students [4,5], adults with ADHD [6], older individuals [7], military veterans with post-traumatic stress [8], and individuals with dementia [9]. Physiological as well as brain neuroplastic changes have been associated in response to participation in mindfulness-based stress reduction programs $[10,11]$, and meditation practice [12-14]; findings which provide clinically rele- vant consequences within the rehabilitative setting.

\section{Discussion}

The upwardly mobile focus surrounding these practices may be partly attributed to the work of Kabat Zinn J [2]. Kabat Zinn J [2] was among the first to introduce the concepts of mindfulness and meditation to the Westernized culture. In his book, initially published in 1998, "Wherever You Go, There You Are", he noted that mindfulness "has nothing to do with Buddhism per se or with becoming a Buddhist, but it has everything to do with waking up and living in harmony with oneself and the world." By providing a theoretical framework for meditation and mindfulness within a non-spiritual context, Kabat Zinn [2] initially opened the door for others with the intention to help them adopt an extremely effective method for self-soothing and anxiety management [2]. The timeline for the increase in peer-reviewed publications falls within the introduction of Kabat Zinn [2] mindfulness training, as well as for alternate programs such as the Koru mindfulness program established by Rogers H \& Maytan M [5]. The latter has been suggested to be effective in improving stress, ameliorating sleep disturbances and increasing self-compassion and mindfulness in students [13].

\section{Conclusion}

Despite the overall increase in peer-reviewed publications within the medical and scientific literature, there still remain a relatively scant number emphasizing the therapeutic use of mindfulness-based or meditative interventions within clinical rehabilitation settings. In physical therapy practice, the number of peer-reviewed studies are exceedingly low suggesting minimal investigation within this discipline despite the conducive nature of this setting to use such approaches. Many practicing physical therapists, for example, use breathing methods as part of their "normal" rehabilitative efforts to treat those patients with respiratory deficits (i.e. through the use of diaphragmatic and pursed lip breathing), it is thus not unreasonable to expand this method to include approaches of mindfulness and meditation to these and other patient populations.

\section{References}

1. Chodron P (1997) When things fall apart. Heart advice for difficult times. ( $1^{\text {st }}$ edn), Shambala Publications, Boston, MA, USA, p. 13.

2. Kabat Zinn J (1994) Wherever you go, there you are. MJF Books, New York, USA, pp. 3-7.

3. Dean S, Peng W, Zaslawski C, Elliot D, Newton John TK, et al. (2017) Mindfulness in physical and occupational therapy education and practice: A scoping review. Phys Ther Reviews 22(5-6): 221-228.

4. Stillwell SB, Vermeesch AL, Scott JG (2017) Interventions to reduce perceived stress among graduate students: A systematic review with implications for evidence-based practice. Worldviews Evid Based Nurs 14(6): 507-513.

5. Greeson JM, Juberg M, Maytan M, James K, Rogers H (2014) A randomized controlled trial of: A mindfulness program for college 
students and other emerging adults. J Amer College Health 62(4): 222233.

6. Hoxhaj E, Sadohara C, Borel P, D’Amelio R, Sobanski E, et al. (2018) Mindfulness vs. psychoeducation in adult ADHD: a randomized controlled trial. Eur Arch Psychiatry Clin Neurosci 268(4): 321-335.

7. Oken BS, Goodrich E, Klee D, Memmott T, Proulx J (2018) Predictors of improvements in mental health from mindfulness meditation in stressed older adults. Altern Ther Health Med 24(1): 48-55.

8. Cushing RE, Braun KL (2018) Mind-body therapy for military veterans with post-traumatic stress disorder: A systematic review. J Altern Complement Med 24(2): 106-114.

9. Chan J, Churcher CA, Royan L, Stott J, Spector A (2017) A mindfulness program manual for people with dementia. Behav Modif 41(6): 764787.

This work is licensed under Creative Commons Attribution 4.0 License

DOI: 10.19080/JYP.2018.05.555669
10. Reiner K, Tibi L, Lipsitz JD (2013) Do mindfulness-based interventions reduce pain intensity? A critical review of the literature, Pain Med 14(2): 230-242.

11. Pelletier R, Higgins J, Bourbonnais D (2015) Addressing neuroplastic changes in distributed areas of the nervous system associated with chronic musculoskeletal disorders. Phys Ther 95(11): 1582-1591.

12. Lazar SW, Kerr CE, Wasserman RH, Gray JR, Greve DN, et al. (2005) Meditation experience is associated with increased cortical thickness. Neuroreport 16(17): 1893-1897.

13. Lumma AL, Kok BE, Singer T (2015) Is meditation always relaxing? Investigating heart rate, heart rate variability, experienced effort and likeability during training of three types of meditation. Int J Psychphysiology 97(1): 38-45.

14. Vestergaard Poulen P, Van Bee M, Skewes J, Bjaram CR, Stubberup M, et al. (2009) Long-term meditation is associated with increased gray

\section{Your next submission with Juniper Publishers will reach you the below assets}

- Quality Editorial service

- Swift Peer Review

- Reprints availability

- E-prints Service

- Manuscript Podcast for convenient understanding

- Global attainment for your research

- Manuscript accessibility in different formats

( Pdf, E-pub, Full Text, Audio)

- Unceasing customer service

Track the below URL for one-step submission https://juniperpublishers.com/online-submission.php 